Journal of Applied Sciences 4 (4): 596-604, 2004

ISSN $1607-8926$

(C) 2004 Asian Network for Scientific Information

\title{
Spatial Decision Support System for Assessing Micro, Mini and Small Hydel Potential
}

\author{
${ }^{1}$ T.V. Ramachandra, Rajeev Kumar Jha, S. Vamsee Krishna and B.V. Shruthi \\ Centre for Ecological Sciences, \\ ${ }^{1}$ Centre for Sustainable Technology, Indian Institute of Science, Bangalore 560012, India
}

\begin{abstract}
This study describes the design and implementation of DSS for assessment of Mini, Micro and Small Schemes. The design links a set of modelling, manipulation, spatial analyses and display tools to a structured database that has the facility to store both observed and simulated data. The main hypothesis is that this tool can be used to form a core of practical methodology that will result in more resilient in less time and can be used by decision-making bodies to assess the impacts of various scenarios (e.g.: changes in land use pattern) and to review, cost and benefits of decisions to be made. It also offers means of entering, accessing and interpreting the information for the purpose of sound decision making. Thus, the overall objective of this DSS is the development of set of tools aimed at transforming data into information and aid decisions at different scales.
\end{abstract}

Key words: Catchment area, land use, land cover dynamics, hydropower, electric energy, precipitation, run-of-river plants, stream flow

\section{INTRODUCTION}

Decision Support System (DSS) is a computer-based system for decision makers who deal with semi-structured problems. DSS is designed and implemented to ease and speed up the use of environmental analysis and techniques. It is an interactive, flexible and adaptable computer based information system, specially developed for supporting the solution of a particular ill-structured problem for improved decision making. It utilizes data, provides easy user interface and allows decision maker's own insights. DSS Frame work can be designed and implemented for environmental systems. Spatial DSS (SDSS) refers to those systems based on the use of GIS technology. Geographic Information Systems (GIS) provides an important source of tools and techniques, which can usefully be incorporated in a DSS, which makes use of geographic or spatial data. SDSS has been defined as an interactive, computer-based system designed to support a user or group of users in achieving a higher effectiveness of decision making while solving a semi-structured spatial decision problem. SDSS are designed to help decision-makers solve complex spatial problem $^{[1]}$

It provides a framework for integrating:

1. Analytical modeling capabilities

2. Database management systems

3. Graphical display capabilities

4. Tabular reporting capabilities

5. The decision-maker's expert knowledge.
SDSS assist in strategic decision-making activities considering spatial and temporal variables, which help in regional planning. Energy is an imperative component, playing a pivotal role in development of a region. The focus of regional energy planning is being shifted towards renewable sources and energy conservations considering the diminishing stock and environmental impacts associated with the fossil fuels. DSS assist in decision-making at disaggregated levels, which is required for integrated regional energy planning considering renewable sources and conservation.

Energy from hydel sources is a clean, renewable and reliable energy source that serves national environmental and energy policy objectives. Hydraulic potential is the combination of possible flow and the distribution of the gradients and the hydraulic resource is that fraction of hydraulic potential which is still accusable after allowing for economic considerations ${ }^{[2]}$. Hydro energy is derived from falling water, either from rivers and streams flowing downhill to the sea or to lakes and dams along the river's course due to the force of gravity. The energy of this movement of water, known as kinetic energy, is usually released through friction as the water flows over rocks and sediments on the riverbed. Harnessing the kinetic energy that is by using the force of the flowing water to drive a turbine generates hydro electricity. The amount of

Table 1: Category of hydel power plant

Micro Hydel $<100 \mathrm{~kW}$ Pico

Mini Hydel $1 \mathrm{MW}$ to $3 \mathrm{MW}$

$\underline{\text { Small Hydel }}$
$3 \mathrm{MW}$ to $25 \mathrm{MW}$

Corresponding Author: Dr. T.V. Ramachandra, Energy Research Group, CES RNO 215, Centre for Ecological Sciences, Indian Institute of Science, Bangalore 560 012, India Tel: 9108023600985 / 22933099 / 22932506 Fax: 9108023601428 / 23600085 / 23600683 [CES TVR] E-mail: cestvr@ces.iisc.ernet.in 
kinetic energy stored in moving water is directly related to the volume of water and the velocity, due to pressure, with which the water flows. Hydropower, large and small, remains by far the most important renewable source for electric power production.

Large-scale hydroelectric power projects are economically unviable when ecological aspects are included. Post reservoir construction studies show that, large hydel projects have been responsible for massive and dramatic ecological changes in the rivers, especially below hypolimnial discharge $\mathrm{e}^{[3]}$. Increased understanding and awareness of complex technical, environment and social issues (inherent to large dam projects), realization that the development of large dam project involves a trade-off between the benefits gained against losses ${ }^{[4]}$ and to ensure environmental sustainability, the focus has shifted towards the development of micro, mini and small hydropower plants.

Mini, micro and small hydro plants combine the advantages of large hydro plants on one hand and decentralized power supply on the other. Small-scale hydro in most cases "run-of-river", with no dam or water storage and is one of the most cost effective and environmental benevolent energy technologies ${ }^{[5]}$. Table 1 shows the category of hydro power plant based on quantity of water and head available at a particular location. These can divert only potential energy of the water, which would have been dissipated to no benefit in the natural flow. The disadvantages associated with large hydro power plants, high transmission costs, environmental costs of submergence of prime lands (forests, crop lands, etc.), displacement of families etc., are not present in the case of small plants. Moreover, the harnessing of local resources, like hydro energy, being of a decentralized nature, lends itself to decentralized utilization, local implementation and management, rural development mainly based on self reliance and the use of natural, local resources.

World's technically feasible hydro potential is estimated at $14,370 \mathrm{TWh} /$ year, which equates to $100 \%$ of today's global electricity demand. The economically feasible proportion of this is currently considered to be $8080 \mathrm{TWh} /$ year $^{[6]}$. Karnataka has a potential of developing $7500 \mathrm{MW}$ of hydroelectric projects, of which only 2755 MW constituting about $36.75 \%$ of the potential has been exploited. Large-scale hydroelectric schemes have been producing power in Karnataka State for many years, with the first hydroelectric power station built in 1902 . Due to environmental constraints further construction of storage reservoir is limited and attention is now focused to develop small-scale hydro schemes in an environmental friendly way to cater the needs of the region ${ }^{[7]}$. KPCL has identified in more than 166 locations in the state for small hydro power plants about $700 \mathrm{MW}$. The potential sources of small hydropower are at the base of existing irrigation dams, anicuts, canal drops and hill streams. The state government has so far accorded permission to private developers to establish small hydro projects in more than 79 locations amounting to $465 \mathrm{MW}$. Private developers have commissioned eight projects ${ }^{[8]}$ with an installed capacity of $49 \mathrm{MW}$. In the case of Mini/Micro hydel projects about 30 locations netting 40.37 MW capacity were identified of which 17.20 MW capacity projects have already been installed in 12 different locations ${ }^{[9]}$.

Criteria for hydel site selection: The choice of site is based on a close interaction between the various conditions like-the pattern of the river, integrity of the site works, environmental integration and conditions defining the costs and benefits ${ }^{[2]}$. It is necessary to establish the inventory of energy demand in various sectors and assessment of various other sources like solar, biomass, wind, etc. Various factors considered while estimating hydro potential are:

! Topography,

! The head (elevation difference),

! Land use pattern in the catchment,

! Hydrological pattern: defined from measurements or from inter-relationships between effective rain and discharge,

! Usage of water, upstream of the intake to determine the flow which is available and downstream to determine the effects of diverting the water from present and future uses,

! Distance from the intake to the power station and from the power station to the consumer site and

! Size of the scheme involved and evaluation of their stability depending on various lithological, morphological and topographical conditions.

The objective of this study was to design a decision support system, which helps in planning and assessing the potential of hydro resources, location wise that can be exploited to meet the regional energy demand in a decentralised way.

\section{MATERIALS AND METHODS}

The DSS of Hydro energy assessment shown in Fig. 1, is a Graphic User Interface (GUI), developed using Microsoft Visual Basic 6.0 as front end with MS Access database as backend. This GUI Environment helps in entry, edit or update of database along with the options to compute power and energy at selected locations.

Measurement of catchment area: Catchment boundaries are located with the help of GIS using the contour lines on 


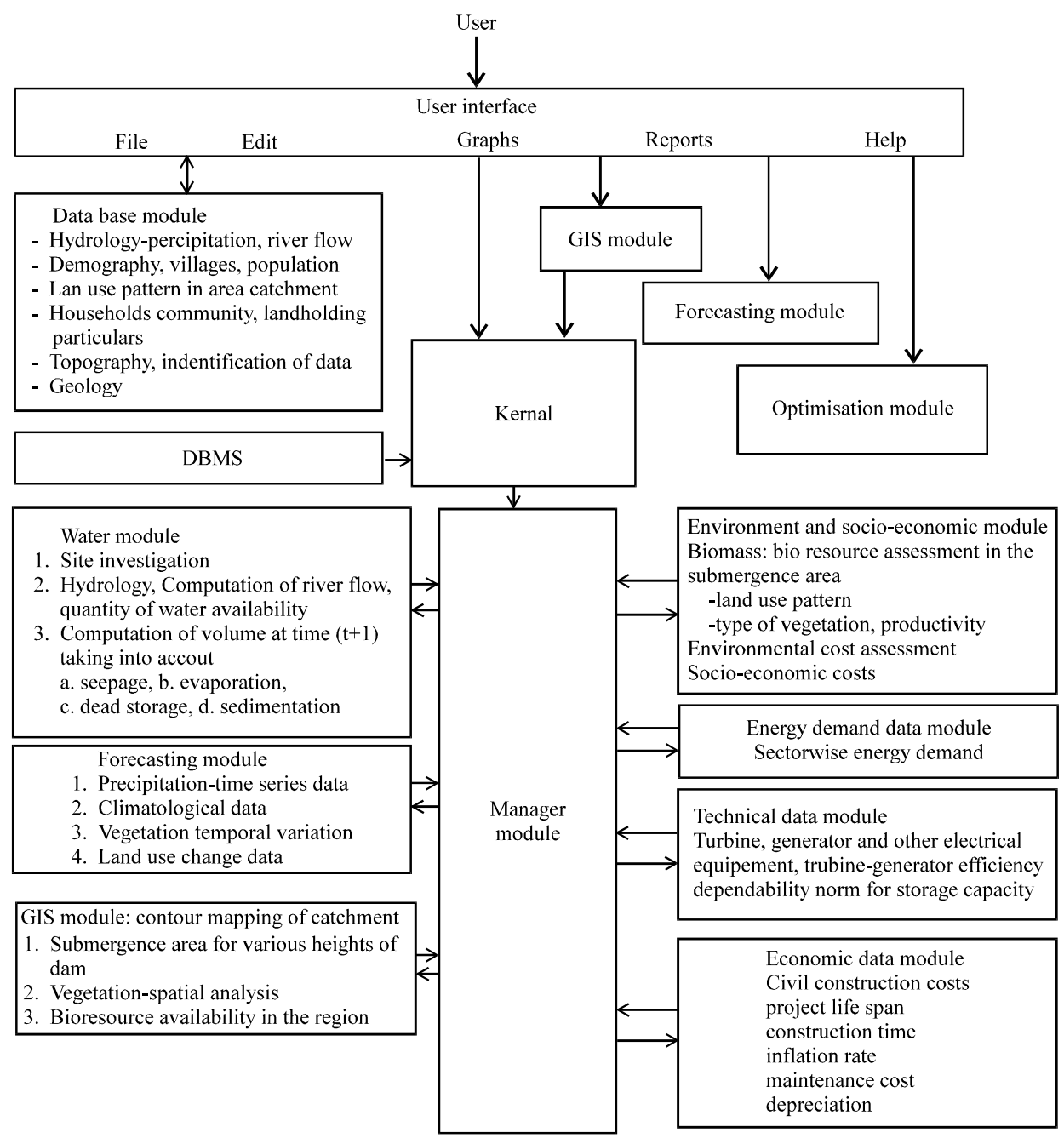

Fig. 1: Design of decision support system for hydro energy assessment

a topographical map. Boundaries are drawn following the ridge tops, which appear on toposheet as downhill pointing V-shaped crenulations. The boundary should be perpendicular to the contour lines it intersects. The tops of mountains are often marked, as dots on a map and the location of roads, which follow ridges, are other clues. The catchment area thus marked/traced is measured directly from the marked maps using a planimeter.

Land use analyses in the catchment area: Land use is the use of land by humans, usually with emphasis on the functional role of land such as land under forests, agriculture, plantation, pastures, etc. Land use pattern in the catchment has direct implications on hydrological yield. Also, construction of hydropower plants across any river or stream will have a direct impact on the land use pattern. Land use analyses are done using remote sensing and GIS.
Stream discharge: Estimation of stream discharge could be done either by direct or by indirect methods.

Direct estimation of flows at site: Stream discharge is the rate at which a volume of water passes through a crosssectional area per unit time. It is usually expressed in units of cubic meters per second $\left(\mathrm{m}^{3} \mathrm{sG}\right)$. The velocity-area method using a current meter is used for estimating discharge. The cup type current meter is used in a section of a stream, in which water flows smoothly and the velocity is reasonably uniform in the cross-section. This measurement is normally carried out for three consecutive days every month for 18 months in order to take into account day-to-day fluctuations and also seasonal variations.

Indirect estimation of flows at site: Runoff is the balance of rainwater, which flows or runs over the natural ground 
surface after losses by evaporation, interception and infiltration. The yield of a catchment area is the net quantity of water available for storage, after all losses, for the purpose of water resource utilization and planning. The runoff from rainfall was estimated by empirical and rational methods:

1. Empirical formula: the relationship between runoff and precipitation is determined by regression analyses based on our field data.

Empirical relation between variables runoff and precipitation is given by Eq. 1:

$$
\mathrm{R}=0.849 * \mathrm{P} * 30.5
$$

Where, R: runoff, P: rainfall in $\mathrm{cm}$.

2. Rational method: a rational approach is used to obtain the yield of a catchment area by assuming a suitable runoff coefficient.

$$
\text { Yield }=C^{*} A * P
$$

Where, C: runoff coefficient, A: catchment area and $\mathrm{P}$ : rainfall. The value of $\mathrm{C}$ varies depending on the soil type, vegetation, geology, etc. From 0.1 to 0.2 (heavy forest), 0.2 to 0.3 (sandy soil), 0.3 to 0.4 (cultivated absorbent soil), 0.4 to 0.6 (cultivated or covered with vegetation), 0.6 to 0.8 (slightly permeable, bare) to 0.8 to 1.0 (rocky and impermeable).

Stream flow and precipitation: Distributions of annual river and stream flows are affected by physiographic factors of a watershed area apart from its precipitation. The literature regarding watershed response can be classified into two general groups. The majority of the research has dealt with obtaining the time distributions of direct surface runoff at a point, given the volume and distribution of the effective rainfall. The remaining part deals with the total rainfall-runoff relationship, including estimation of the volume of effective rainfall and considering loss functions experienced by storm rainfall. Studies regarding the conversion of effective rainfall to hydrographs of stream flow at the catchment/watershed outlet stem primarily from unit hydrograph theory. The theory has been modified, applied, verified and used for analysis and synthesis. The concept of the instantaneous unit hydrograph along with various storage and routing ideas has led to numerous theoretical response models. On the other hand, few rainfall-runoff models have been investigated with emphasis on the conversion of rainfall to effective runoff.
Hydrograph depicts stage, discharge, velocity or other properties of water flow with respect to time. It can be regarded as an integral expression of physiographic and the climatic characteristic that govern the relations between the rainfall and the runoff of a particular drainage basin. A unit hydrograph is the graph resulting from $25 \mathrm{~mm}$ effective rainfall generated uniformly over the basin at a uniform rate during specific period of time or duration. The unit hydro graph procedure can be applied to data from small catchment/watershed. However, the relatively short time unit required makes the derivation of the unit hydrograph a difficult task and as a result, a synthetic hydrograph approach is used. A synthetic hydrograph is prepared using the data from a number of watersheds to develop a dimension less unit hydrograph applicable to ungauged catchment/watershed ${ }^{[10]}$.

Stream flow and ecology are both affected by catchment conditions. Changes in stream discharge and sediment loading, caused by the modification of the catchment area are reflected in variations in the rate of sediment transport, channel shape and stream pattern. Responses to a change may be immediate, delayed or dependent upon a critical factor reaching a threshold level. It is necessary to know the response of catchment/watershed to rainfall in order to design structures, such as overflow spillways on dams, floodprotection works, highway culverts and bridges. The rate at which runoff moves towards the stream is dependent on the drainage efficiency of the hill slopes. Drainage efficiency is influenced by the slope and length of upland surface, its micro topography, the permeability and moisture content of the soil, subsurface geology and vegetation cover. The hydro potential of each stream is assessed so as to have micro, mini or small hydro power plants.

Power and energy: The evaluation of hydropower potential requires knowledge of both the absolute value and the time variability of flow and head. Power (P in kW) is calculated based on flow data and head height, as given in equation 3 . The corresponding electrical energy $(\mathrm{kWh})$ produced is given by Eq. 4:

$$
\begin{aligned}
& \text { Power }=9.81 * \text { Average (flow data) } * \text { Average (head height) } \\
& \text { Energy }=\mathrm{P} * \mathrm{t} * \mathrm{n} * \mathrm{f}
\end{aligned}
$$

Where, $\mathrm{P}$ : power in $\mathrm{kW}$, $\mathrm{t}$ : operating time in hours, $\mathrm{n}$ : efficiency of the turbine generator assembly, $\mathrm{f}$ : coefficient for seasonal flow variation for run of river installation.

DSS validation: DSS is validated with the field data collected for exploring the feasibility of small, micro and 
mini hydel schemes in Uttara Kannada district of Western Ghats.

Study area: Uttara Kannada District located in the mid-western part of Karnataka state is selected for this study. It lies $74^{\circ} 9^{\prime}$ to $75^{\circ} 10^{\prime}$ east longitude and $13^{\circ} 55^{\prime}$ to $15^{\circ} 31^{\prime}$ north latitude and extends over an area of $10291 \mathrm{sq} \mathrm{km}$, which is $5.37 \%$ of the total area of the state, with a population above 12 lakh. It is a region of gentle undulating hills, rising steeply from a narrow coastal strip bordering the Arabian Sea to a plateau at an altitude of $500 \mathrm{~m}$, with occasional hills rising above 600 to $860 \mathrm{~m}$. According to the recent remote sensing data, of the $10291 \mathrm{sq} \mathrm{km}$ geographical area, $67.04 \%$ is under forest, $1.94 \%$ under paddy and millet cultivation, $1.26 \%$ under coconut and areca garden, $1.94 \%$ under rocky outcrops and the balance $27.82 \%$ is under habitation and reservoirs. There are four major rivers-Kalinadi, Bedthi, Aghnashini and Sharavathi. Besides these, many minor streams flow in the district.

This district with 11 taluks can be broadly categorized into three distinct regions-coast lands (Karwar, Ankola, Kumta, Honnavar and Bhatkal taluks), mostly forested Sahyadrian interior (Supa, Yellapur, Sirsi and Siddapura taluks) and the eastern margin where the tableland begins (Haliyal, Yellapur and Mundgod taluks). Climatic conditions ranged from arid to humid due to physiographic conditions ranging from plains, mountains to coast. This large variety of natural conditions provides the basis for generalization of the theoretical probability distributions for annual precipitation. Among the four rivers, the hydro potential of Kali and Sharavathi has been tapped already for power generation. The completed large-scale projects have caused serious environmental damage in the form of submergence of productive natural virgin forests, horticulture and agricultural lands, etc. In view of these, we assess the potential of the Bedthi and Aghnashini rivers and explore ecologically sound means of harnessing the hydro energy.

Catchment area: The catchment area for streams is obtained from the Survey of India toposheets. Stream gauging is done with both direct and indirect methods. Catchment area measured from the marked toposheets using planimeter for the streams in Bedthi and Aghnashini river basins. Along the Bedthi river course drops at various points have been identified: Kalghatgi $(80 \mathrm{~m})$, Kaulgi Halla (64 m), major drop at Magod (of about 340 m) and the lowest drop $8.5 \mathrm{~m}$ is in Ankola taluk, about $129 \mathrm{~km}$ from Kalghatgi. Numerous streams join the river along its course from Kalghatgi. Major streams with good drops (head) are Shivganga (119 m), Handinadi
(230.50-318.50 m) and Matti gatta $(270 \mathrm{~m})$. The Aghnashini river has major drops at Unchalli $(360 \mathrm{~m})$ and the major streams are Benne (400 m drop), Bhimavara (290 m), Mudanalli (270 m), etc.

The average channel slope $\left(S_{c}\right)$ is one of the factors controlling water velocity, while the slope of the catchment $\left(S_{b}\right)$ influences surface runoff rates. These two parameters give an idea about the nature of a stream. Hence $S_{c}$ and $S_{b}$ are computed. Magod has a slope of $61.34^{\circ}$. The Shivganga and Mattigatta streams of the Bedthi catchment have slopes $43.83^{\circ}$ and $40.03^{\circ}$, while Muregar and Boosangeri have slopes of $6.27^{\circ}$ and $2.29^{\circ}$. The Muregar jog has a catchment of $25.97 \mathrm{sq} \mathrm{km}$, while Boosangeri has $11.29 \mathrm{sq} \mathrm{km}$. Stream gauging at regular intervals is carried out in Muregar, Boosangeri, Vanalli and Shivganga.

\section{RESULTS AND DISCUSSION}

An executable file is provided for this application and by executing, the login form is displayed as given in Fig. 2. This allows a user to enter the name and organization for existing users and new users are prompted to create a new profile. The main menu contains Login, Hydro module, Help, Exit. Hydro menu module as shown in Fig. 3, has sub menu;

\section{! Mini/Micro/Small Hydel projects \\ ! Data display}

The menu option Mini/Micro/Small allows user to enter general information such as location details, Flow data, Period (yearly/monthly/daily), Method for assessment of energy. User is allowed to enter the head height details if flow data is known. The Query option gives the average precipitation. Figure 4 provides average flow calculation. If there is no flow data then the user is allowed to choose any of indirect methods i.e., Empirical or Rational method as given in Fig. 5. If there is no precipitation data then user is allowed to choose data from near by station (IMD observatory station).

Stream gauging is carried out using a current meter every month. Stream discharge ranges from 1.12 (August) to $0.015 \mathrm{~m}^{3} \mathrm{sG}$ (in February) for Boosangeri. In the case of Muregar, it ranges from 1.395 to $0.026 \mathrm{~m}^{3} \mathrm{sG}$. This indicates that streams of this kind are seasonal. Power generated during June to September is sufficient to meet the energy needs of the nearby villages.

Empirical method: Empirical relation between variables runoff and precipitation is given in DSS (equation 1). If the user selects Empirical method then the query option 
J. Applied Sci., 4 (4): 596-604, 2004

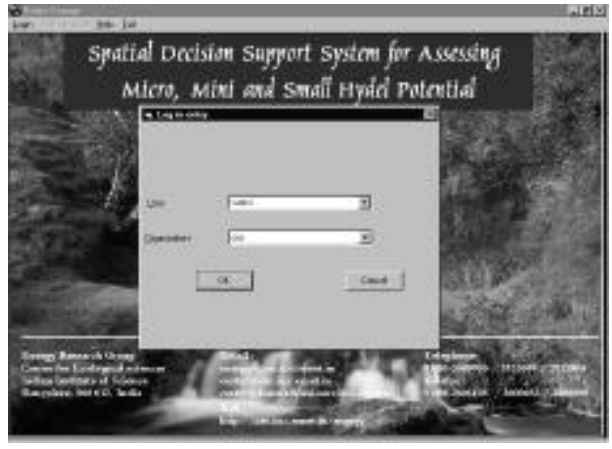

Fig. 2: Login screen

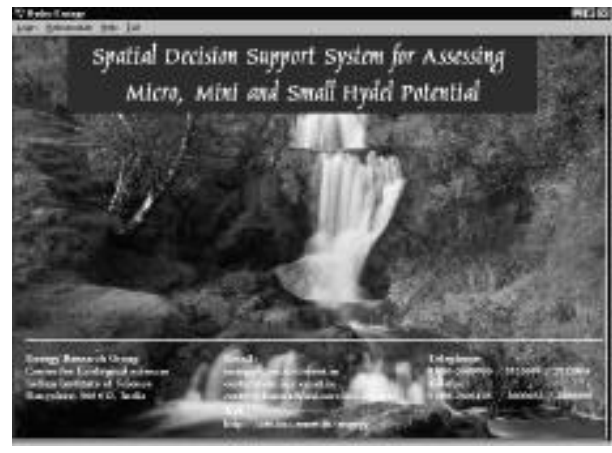

Fig. 3: Hydro menu module

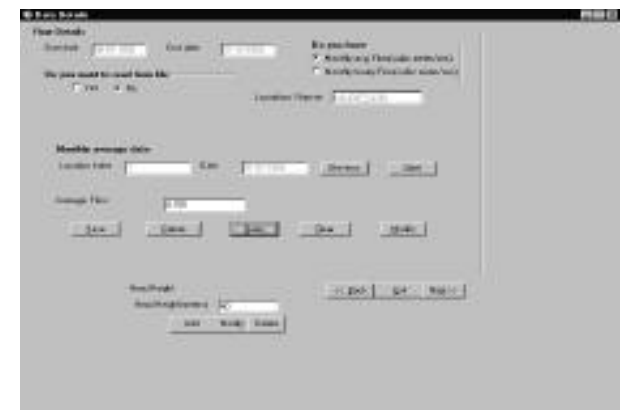

Fig. 4: Average flow calculation

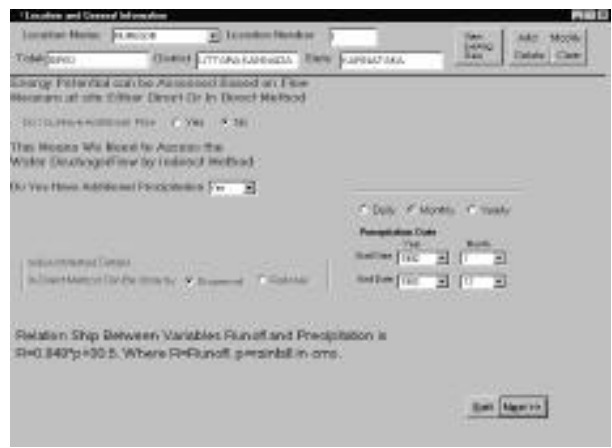

Fig. 5: General information empirical method

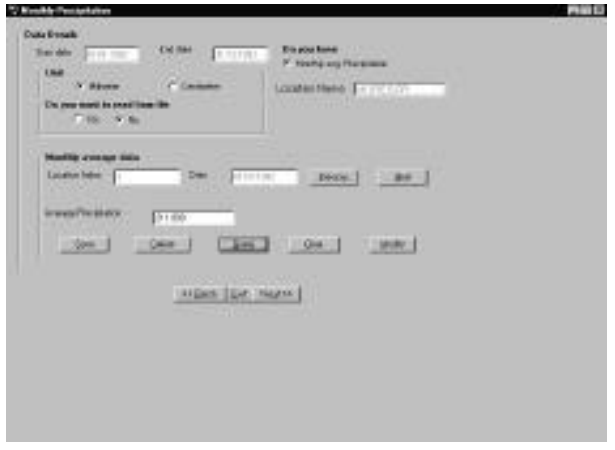

Fig. 6: Average precipitation

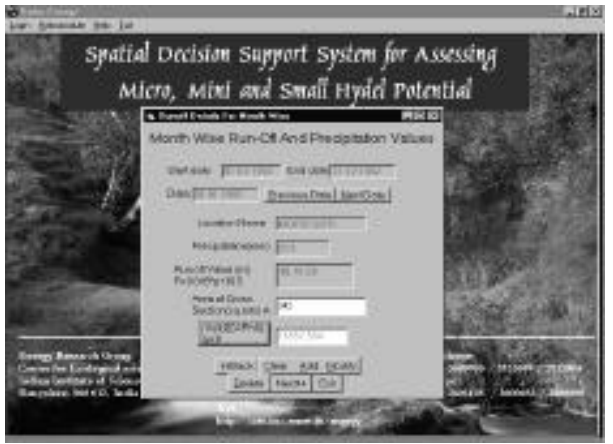

Fig. 7: Yield calculation

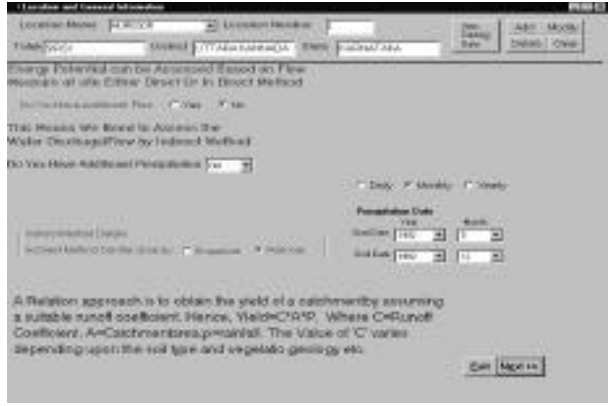

Fig. 8: General information on rational method

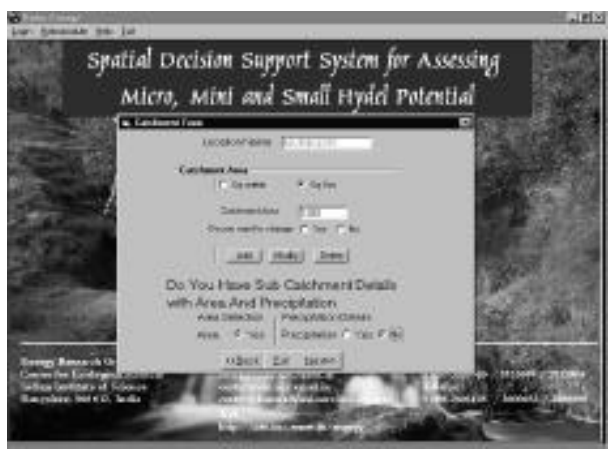

Fig. 9: Catchment area 


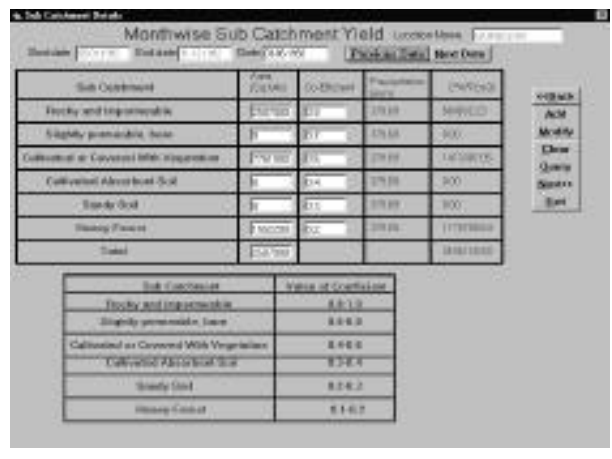

Fig. 10: Sub-catchment area yield

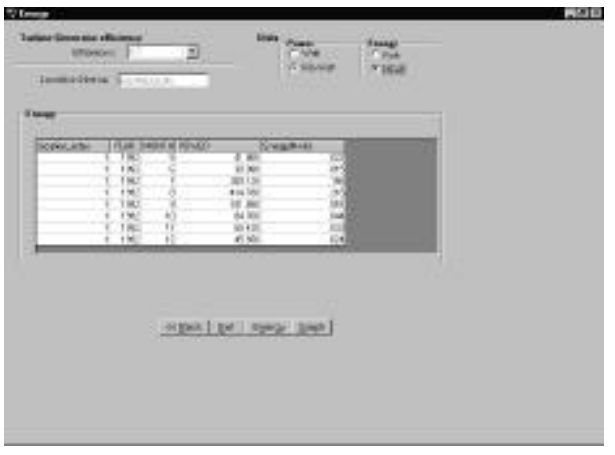

Fig. 11: Energy calculation

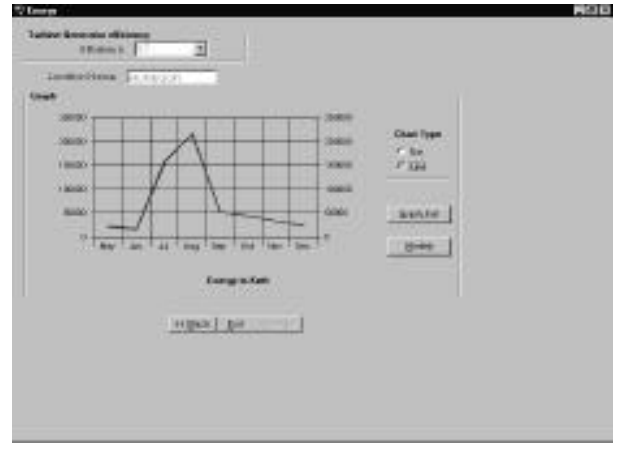

Fig. 12: Energy variation with respect to time (direct method)

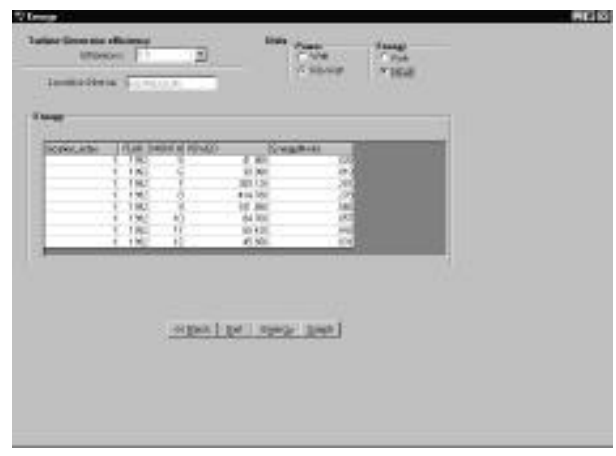

Fig. 13: Power and energy calculation

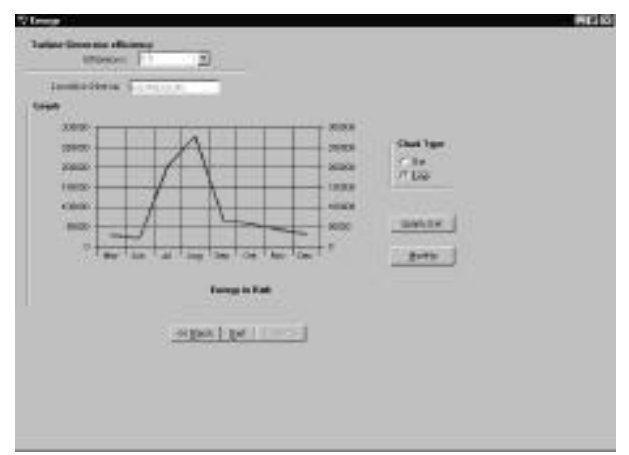

Fig. 14: Energy variation with respect to time (empirical method)

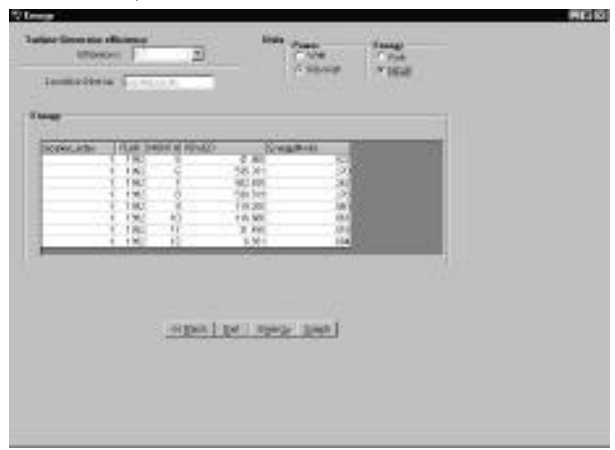

Fig. 15: Energy calculation

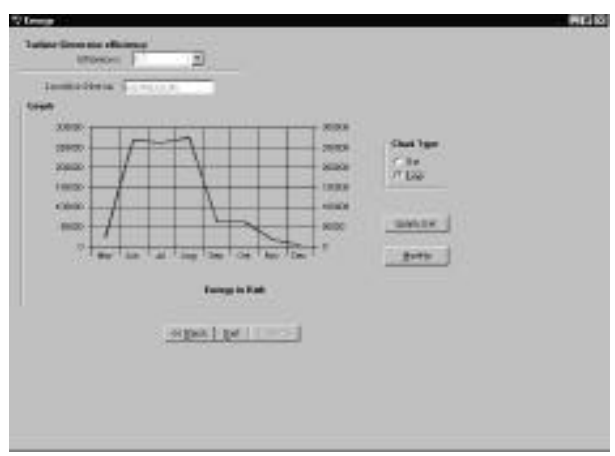

Fig. 16: Energyy variation with respect to time (relational method)

gives the average precipitation as shown in Fig. 6. The Next option as shown in Fig. 7 prompts the user to enter area of cross section in sq.m and calculates yield based on the values of Precipitation and runoff.

Rational method: Figure 8 is shown if rational method is chosen. This method is a relation approach to obtain the Yield of catchment by assuming a suitable runoff coefficient, which varies, based on soil type, vegetation, geology etc. Next option displays the catchment area and prompts user whether precipitation details are available or not as shown in Fig. 9. If 
the precipitation details are available then user is allowed to enter Sub-catchment details as given in Fig. 10. The Query option calculates precipitation and yield based on the sub-catchment area and co-efficient.

In order to estimate the hydropower potential of ungauged streams, either the rational or empirical relationship of runoff and precipitation is used. The study employs rational method for estimating the hydro energy potential.

A suitable runoff coefficient (which depends on catchment type) is assumed to derive monthly yield in rational method. For each site, Yield (Y) is computed with the knowledge of catchment area (A), catchment coefficient $(\mathrm{C}$ and precipitation $(\mathrm{P})$ using equation 2 . An attempt has been made to compute the monthly yield from catchments by this method and subsequently the power that could be harvested from the streams. This corresponds with the power computed by the direct method (of the gauged streams Boosangeri and Muregar). Hence, rational method is used to compute hydropower of ungauged streams.

Power and energy calculation: Power is calculated based on flow data and head height, as given by equation 3 . Energy option calculates hydro energy based on turbine generator efficiency, period and power as given by equation 5. Figure 11 gives energy calculation. By pressing Graph button, user will be able to view Graph form. It displays graphical representation of hydro energy variation with respect to time as shown in Fig. 12.

Figure 13 gives the option to calculate power and hydro energy using empirical method. Graphical representation of hydro energy derived from empirical method is displayed by graph option as shown in Fig. 14. The values obtained from the sub catchment yield are used to calculate power using rational method. This power is used to calculate energy as given in Fig. 15. Graph option displays graphical representation of energy derived from rational method as shown in Fig. 16.

The study explores the possibility of harnessing hydro potential in an ecologically sound way (by having run-of-river plants with no storage options) to suit the requirements of the region. The Sirsi, Siddapur and Yellapur taluks in hilly terrain amidst evergreen forests with a large number of streams are ideally suitable for micro, mini or small hydro power plants. Monthly stream gauging at Muregar and Boosangeri has revealed that mini hydro power plants could be set up at these sites. The stream at Muregar is perennial, with a flow of about $0.26 \mathrm{~m}^{3} \mathrm{sG}$ during summer and power of the order of $10-20 \mathrm{~kW}$ could be generated, while during the monsoon power of $300-400 \mathrm{~kW}$ could be harnessed.
Computations of discharge by the empirical or rational method, considering precipitation history of the last 90 years and the subsequent power calculated is in conformity with the power calculations done based on stream gauging. Based on this field experience of gauged sites, an attempt has been made to compute water inflow (using the indirect method), hydraulic power available and energy that could be harnessed monthly for all ungauged streams in the Bedthi and Aghnashini river catchments. It is estimated that about 720 and 510 million $\mathrm{k} \mathrm{Wh}$ of energy can be generated from various streams in Bedthi and Aghnashini catchments.

\section{CONCLUSION}

Hydroelectric power has always been an important part of the world's electricity supply, providing reliable, cost effective electricity and will continue to do so in the future. Mini micro and small hydro are non-consumptive generators of electrical energy, utilizing a renewable resource, which is made continually available through the hydrological cycle. These hydro power stations provide an ideal method of producing electricity in rural and mountainous area where the demand is scattered and relatively low, provided that the water resources are available and that the ground has some raised areas.

The technologies and method used to develop and deploy DSS to aid in hydro energy assessment make, work easier for a decision maker. The possibility of quickly accessing and processing large spatially databases over high speeds offer a tremendous improvement. In spite of rapidly advancing computer technology and the proliferation of software for decision support, relatively few DSS have been developed for assessment of hydro energy. This DSS is a User-friendly GUI, which provides user with all needs to estimate and calculate hydro energy at different locations with different conditions for Micro, Mini and Small Hydro plants. The entire framework is designed in a way such that, user is provided with helpful tips and context-sensitive help options.

\section{ACKNOWLEDGMENTS}

We thank Ministry of Science and Technology, Government of India and Indian Institute of Science for the infrastructure support and financial assistance. Mr. Mahesh Babu assisted in the initial stages of GUI development. Mr. Rosario, Mr. Raghavendra Rao and Mr. Deepak Shetti assisted us in the field data collection. We are grateful to Mr. Sanjeev Kumar Jha for proof reading the document and for suggestions. 


\section{REFERENCES}

1. http://www.geog.ubc.ca/courses/klink/gis.notes/nc gia/u59.html

2. Monition, L., M. Le Nir and J. Roux, 1984. Micro Hydroelectric Power Stations. John Wiley and Sons, St Edmundsbury Press, Bury St Edmunds, Suffolk.

3. Langford, T., 1983. Electricity Generation and the Ecology of Natural Water. Liverpool University Press, Liverpool, England.

4. Tony Dorcey, 1997. Large Dams-Learning from the Past to Looking at the Future. Workshop Proceedings. Gland, Switzerland.

5. Oliver Paish, 2002. Small hydropower: technology and current status. Renewable and Sustainable Energy Reviews, 6: 537-556.
6. Fraenkel, P., O. Paish, V. Bokalders, A. Harvey, A. Brown and R. Edwards, 2002. Micro-Hydro Power: a guide for development workers, 1991. In. Oliver Paish. Small hydropower: technology and current status. Renewable and Sustainable Energy Reviews, 6: 537-556.

7. Ramachandra, T.V., D.K. Subramanian and N.V. Joshi, 1995. Micro, Mini and Small Hydel Potential in Uttara Kannada District, Karnataka. Rural Technol. J., 13: 121-138.

8. http://www.nitpu3.kar.nic.in/kredl/venture/frsmall.htm

9. http://www.teriin.org/renew/tech/hydro/present.htm

10. Ven Te Chow, 1964. Hand Book of Applied Hydrology. McGraw-Hill, Inc., USA. 